Please quote as: Dünnebeil, S.; Sunyaev, A.; Leimeister, J. M. \& Krcmar, H. (2013): Modular Architecture of Value-Added Applications for German Healthcare Telematics. In: Business \& Information Systems Engineering (BISE), Ausgabe/Number: 1, Vol. 5, Erscheinungsjahr/Year: 2013. Seiten/Pages: 3-16; DOI: 10.1007/s12599-012-0243-3. 


\section{Modular Architecture of Value-Added Applications for German Healthcare Telematics}

The electronic health card and the telematics infrastructure are widely discussed in the German public. However, the applications which aim at improving the healthcare system by utilizing the capabilities of the service oriented healthcare telematics have hardly been addressed so far. The article discusses the potential of such value-added applications that are not subject to the limitations of current information systems in medical institutions and open up new potentials. To this end, overall requirements of value-added applications based on the architecture are illustrated by implementing a collaborative application for referral and appointment management. The issues security, interoperability, patient orientation, and system integration are of major interest.

\section{The Authors}

Sebastian Dünnebeil, M.Sc. Prof. Dr. Helmut Krcmar Chair for Information Systems Department of Informatics Technische Universität München Boltzmannstrasse 3 85748 Garching near Munich Germany sebastian.duennebeil@in.tum.de krcmar@in.tum.de

\section{Dr. Ali Sunyaev ( $\varangle)$}

Information Systems and Information Systems Quality

Faculty of Management,

Economics and Social Sciences

University of Cologne

Pohligstr. 1

50969 Cologne

Germany

sunyaev@wiso.uni-koeln.de url: http://www.isq.uni-koeln.de

Prof. Dr. Jan Marco Leimeister Fachgebiet Wirtschaftsinformatik Chair for Information Systems Kassel University Nora-Platiel-Str. 4 Raum 1102

34127 Kassel

Germany

$$
\text { and }
$$

Institute of Information Management (IWI HSG)

University of St. Gallen

St. Gallen

Switzerland

JanMarco.Leimeister@unisg.ch
Received: 2012-03-01

Accepted: 2012-10-06

Accepted after two revisions by

Prof. Dr. Kim.

Published online: 2013-01-08

This article is also available in German in print and via http://www. wirtschaftsinformatik.de: Dünnebeil S, Sunyaev A, Leimeister JM, Krcmar H (2012) Modulare Softwarearchitektur für Mehrwertanwendungen der deutschen. Gesundheitstelematik. WIRTSCHAFTSINFORMATIK. doi: 10.1007/s11576-012-0345-z.

Electronic Supplementary Material The online version of this article (doi: 10.1007/s12599-012-0243-3) contains supplementary material, which is available to authorized users.

(c) Springer Fachmedien Wiesbaden 2013

\section{Introduction}

Public discussion about the initiation of the electronic Health Card (eHC) in combination with a standardized network in German healthcare has been going on for years. The date of introduction, originally planned for 2006 , has long since gone by; a networking of service providers involved in healthcare is still not in sight (Tuffs 2010).
Specifically, there is enormous opposition from physicians against activities for the construction of a German telematics infrastructure (TI). They fear that the eHC, which includes governmental requirements for specific services, will bring along a larger workload and no corresponding financial compensation (Allensbach 2010), without the benefit of an additional value for the medical core processes (Kirn 2005; Mertens 2012). Especially the idea of a permanent central storage of patients' data in electronic files was categorically rejected (Dünnebeil et al. 2010b). The "Deutsche Ärztetag", central committee of German medical doctors, dismissed the project in all ballots and requested a new foundation for the initiative, to adequately consider the needs of physicians (BITKOM 2009). In 2009, responsibilities for the eHC were turned over to the medical professional associations to bring it in line with the intentions of the doctors.

At the same time, the German health system shows "[...] a transition from a regulative system which is still predominantly centrally and collectively planned towards a definitely free organization of contracts between insurances and service providers [...]" (Jacobs and Schulze 2004). Individually configured processes are to organize healthcare among patients, service providers, and cost bearers with regard to each separate case and require ever more support from IS networks. These have so far found no consideration in the efforts to specify health telematics. Case-oriented require- 
ments and care processes, which integrated care concepts have started to contemplate (Silber 2006), cannot be represented adequately in presently specified telematics services. Instead, governmental applications of TI so far take their baring from collective care processes of the regular care provided by law.

The eHC's value-added applications (VAA) are not specified by governmental institutions. Instead, they are supposed to facilitate the development of innovative information techniques in the service providers' institutions, engineered by independent firms, insurances, or research institutes on the basis of TI (Neuhaus et al. 2006; Rohner and Winter 2008). Applications for mobile device applications could serve as models. These are developed by a distributed global engineering community, presenting an added value for many users (Holzer and Ondrus 2011). It is unclear how similar potentials for VAA around the eHC can be raised by constructing approaches allowing for a reliable implementation of practical user scenarios. In view of the opposition against the services rendered by the eHC specified by governmental rules, there is an apparent need for the design of reference architecture of VAA of the TI which is widely accepted by user groups. The understandable worries of physicians should be taken into account by integrating the main criticism of doctors in the software architecture of TI applications. The simultaneous installation of practical user scenarios should ensure a high degree of acceptance. Furthermore, modular reference architecture should improve specification, implementation, and re-use of well-defined components.

This article aims for the demonstration of VAA's relevance for German healthcare and for the design of modular software architecture for VAA of TI according to the requirements of service providers, demonstrating its usefulness and manageability in an exemplary implementation. It also intends to convey, beside a description of the architecture, useful approaches to the development of the eHC's VAA for German healthcare, which could eventually result in a comprehensive reference model. It is a specific aim to describe communication between distributed applications (e.g., in clinical practices) without joint project management. In healthcare, especially with small or lacking IT-departments, architectural decisions are usually neglected (Köbler et al. 2010). We therefore address the following questions to research:
- Which overall requirements exist for VAAs of the eHC?

- Which modular architecture can provide suitable structures for these overall requirements?

- Which implications arise from the implementation of an exemplary application?

\subsection{Status Quo of Medical Information Systems in German Healthcare}

For decades, medical information systems (MIS) have been used by general practitioners and medical specialists, which support the doctors in the medical and administrative procedures of their treatments. Since January 1, 2011 online accounting by means of a system authorized by the German "Association of Statutory Health Insurance Physicians" (ASHIP) has been compulsory (KBV 2010). At the time of writing this article, 156 different systems were authorized by ASHIP for online accounting (KBV 2011a). MIS today possess a number of additional functions, such as calendar management, files of patients, or databanks for medication, and have grown to be an essential part of the daily routine of registered doctors (Dünnebeil et al. 2010a). A structured medical communication between the systems of different providers has only scarcely been established to date. The project of eHC was started in Germany because there are processes in healthcare which comprise various institutions all needing the support of IT systems (BMG 2005). To enable a safe, operational exchange of patients data between the systems of different providers, the specification of a comprehensive TI was started on in 2004 (Fraunhofer 2005).

\subsection{German Telematics Infrastructure}

German TI is in line with the paradigm of service-oriented architectures (SOA). Exchange services for medical data are offered as XML web-services (Fig. 1). It is planned that the systems of all participants in healthcare make use of these services (gematik 2009a). Providers of health services may select web services of the eHC within the frame of uniform and universally available specifications of gematik ("Gesellschaft für Telematikanwendungen der Gesundheitskarte) (gematik 2012). Thus uniform standards of communication are established which ensure interoperability, safety and compliance with statutory requirements. A current detailed technical description of the German telematics infrastructure can be found with Dehling and Sunyaev (2012).

The services of TI can be divided into three classes:

TI provides basic services in the form of local or central web services enabling the use of uniform procedures for authentication, authorization, signatures, and codification in the applications. Basic services are specified by gematik, guarantee a comprehensive level of safety, and comply with legal directives, such as the possibility to sign and the visibility of patients' data. All services are available via the connector, offering interfaces as predefined web services. In medical practices this connector is a hardware component with an imbedded system. The connector provides local services, like codification, digital signature, or e-card management and creates a connection, if necessary, with the central services of TI (gematik 2009b).

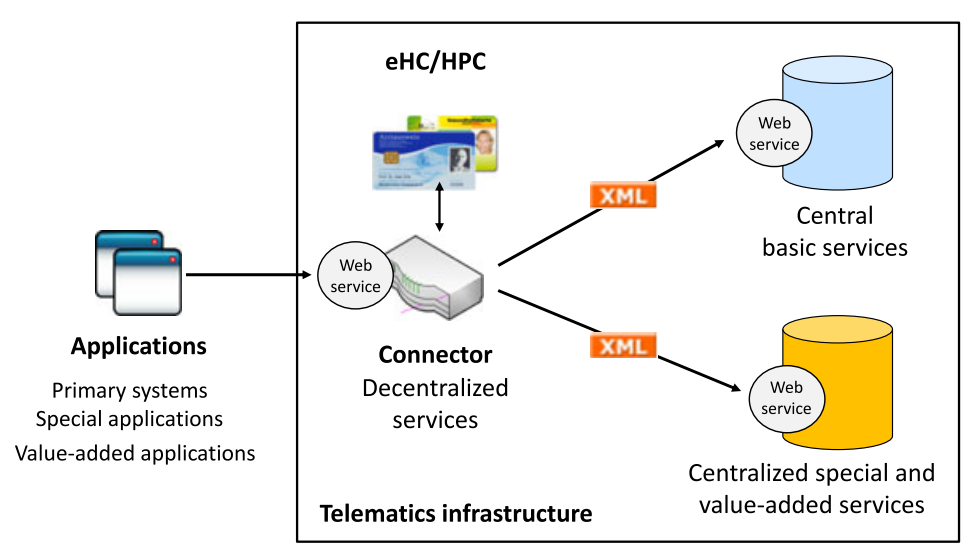

Fig. 1 Telematics infrastructure 
Medical and administrative special services are also specified by gematik. Their use may be obligatory, as in the comparison of basic data of the insured, or voluntary, as in the creating of an emergency record. Among the voluntary services an electronic health record was planned, to provide all authorized doctors with a patient's medical data via a central service (gematik 2009a). No specifications for such a service exist so far, the realization of this project is quite uncertain due to its low acceptance (Allensbach 2010).

Value-added services (VAS) of TI may be specified by various organizations and are supposed to provide one or more user groups of health telematics, e.g., patients, physicians, caregivers, or pharmacists, with an additional value. ASHIP was asked to design a VAS specification for the communication between service providers. This is meant to ensure the safe communication of uniform medical correspondence between healthcare organizations and uses telematics services for digital signatures, codification, or directory services. Further VAS seem possible in order to provide for functions necessary for structural treatments (VHitG 2006). In the long run, VAS should grant TI the largest financial benefit, up to $€ 2.5$ billion savings per year according to an economic analysis (Bernnat 2006).

\subsection{Clients of TI}

At the time of the eHC's specification (2004), distribution of applications on ubiquitous and mobile devices was not yet widely spread; therefore, they were not considered typical users of TI. Only the primary systems of service providers in hospitals, pharmacies, and medical practices were originally considered as clients for the described services of the eHC (gematik 2009a). Primary systems are medical IS which support important treatment processes in healthcare institutions. These are normally offered as a proprietary product by specialized firms. In smaller institutions, like medical practices and pharmacies, they usually cover standardized functions only (TURBOMED 2012). It is not possible to anticipate whether a modular enhancement of these systems is aimed at which could open them for a larger number of designers. However, the standardized treatment of patients following a uniform process and sufficiently specified by standard software, is in many cases a thing

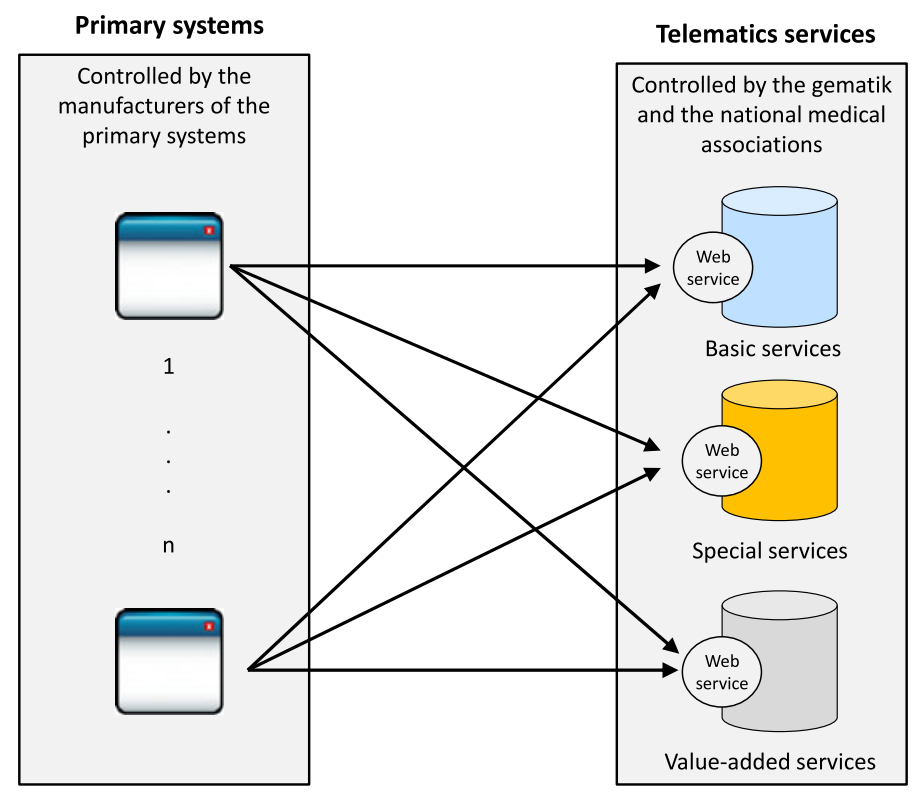

Fig. 2 SOA of German healthcare

of the past. Integrated care contracts according to $\$ 140$ a of the Fifth Book of the Social Statutes (SGB5), which can be agreed upon between insurances and doctors associations (BRD 2004b), follow specific requirements of a region or population and cannot be sufficiently described in standard software (Hornung et al. 2005). In order to support a structured treatment process within a collective of physicians, e.g., coordination and compensation of specialists' dates and hospital referrals, all participating primary systems have to be adapted to the process. To coordinate administrative and medical tasks comprising various institutions which cannot be handled by practices separately, regional doctors' collectives normally use a variety of proprietary MIS. The regional doctors' collective in which this research was conducted consists of a network of 493 registered physicians who use 40 different MIS at the moment (Dünnebeil et al. 2011). The number of MIS makes it impossible to provide global processes on the primary systems, implementing regional requirements without media change, as otherwise an adaptation of up to 40 systems would have to be coordinated with the producers (Fig. 2).

\subsection{Value-Added Applications of TI}

For the above mentioned reasons, the design and providing of VAA is aimed at implementing regionally integrated healthcare processes independently of the use of standardized primary systems. VAA constitute "a (...) distributed application consisting of the sum of all interfaces, protocols, and components necessary for the implementation of a specific use case" (gematik 2009a). These applications, by using the services of eHC, are able to simplify existing processes and tasks or to implement new requirements such as of practice networks or medical care centers (Dünnebeil et al. 2011). Thus, medical institutions obtain the opportunity to introduce their own specifications and use the existing functions of the TI. Figure 3 schematically shows a VAA attempting to depict a quality insured transfer within a doctors' collective. The architecture designed should support the structured development of such applications.

The aim of this paper is to identify, abstract, and record the components for architecture of distributed VAA of TI which are of importance for these applications. In the future, VAA can thus be designed according to a structured architecture (Shaw and Garlan 1996). Particular modules can then be designed, implemented, and re-used stringently. This is supposed to provide the basis for the development of reference architecture of VAA and in the long term of a reference model for decentralized care processes in ambulant healthcare. 


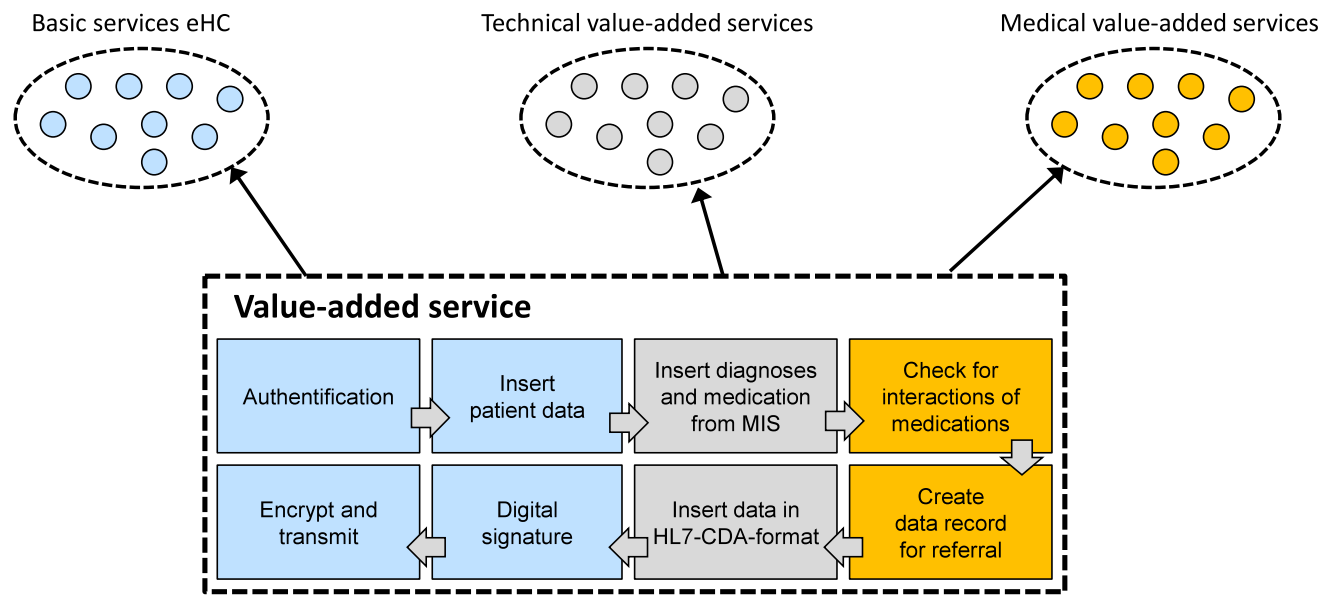

Fig. 3 Structure of VAA for electronic referral

\subsection{Software Architectures in Healthcare}

IS-architecture is a structured abstraction of existing or planned IS, according to Dern (2009). Aims of software architecture are documentation, communication, re-use, basis for systems design, and quality assurance (Hasselbring 2000). Software architectures describe a selection of software components, their interactions and data structures, which derive from requirements and form the basis for the software design. A component in software architecture is a composition unit (Szyperski et al. 2002) which possesses well defined interfaces and explicit correlations and may be implemented independently from others or combined with others. The general design of components or their interactions may be performed by domain independent architectural models. Layer based architectural models help to structure unclear requirements (Buschmann et al. 1996). Service-oriented architectural models as provided for in TI allow a flexible transformation of new processes through initial composition of atomized services (Tsai et al. 2006). According to Vogel et al. (2009) reference architectures combine general architectural knowledge with specific claims for a complete architectural solution in an area serving as a basis for the conception of specific architectures. Reference models, mainly used in information systems research, attempt to show the complete information model of an application as a reference for business models (Fettke and Loos 2002).

Dinh and Chu (2006) classify the healthcare sector as one of the most complex and information intense environments. The reasons given are among others: the complexity of processes (especially of medical pathways), the large number of clinical data formats (e.g., for diagnostics, results, or clinical imaging), the ambiguity of clinical documentation concepts, the high variability of medical files, or the heterogenic organization structures in medical institutions. Existing research structures e-health architectures primarily according to interoperability (Pedersen and Hasselbring 2004), ability of integration (Tsiknakis et al. 2002; Schweiger et al. 2007), security (Blobel 2004; Gritzalis and Lambrinoudakis 2004; Riedl et al. 2008), or according to specific perspectives (Fayn et al. 2003). An Architecture for telematics services was grouped in layers following technical viewpoints (Tsiknakis et al. 1997) and specified as SOA in (Fraunhofer 2005). The latter followed an architecture layered considering security considerations. An architecture for specifically elected applications of TI was roughly described (Frießem et al. 2005), but not sufficiently elaborated to be implemented in heterogenic VAA. The architecture for the application of TI described in this paper is, in dependence of existing e-health architectures, to be built in layers (Dijkstra 1968), as such an approach has proven successful in many Internet applications (Urgaonkar et al. 2007). The successful ISO/OSI reference model (Zimmermann 1980) is used as a guide to describe various tasks of a safe communication between distributed systems in a medical environment. The use of services in SOA can be modularized according to functional criteria to model a structured application (Arsanjani and Allam 2006). When applying service-oriented architectural models, especially for distributed groupware like TI using XML-based data, the composition form has proven to be of value (Marsic 2001). Papazoglou (2003) showed how services, offering mostly atomized functionalities, can be combined in an extended SOA. The architecture of VAA of TI therefore attempts to structure the applications according to functional layers deriving from requirements posed by the users.

\section{Research Methods}

This paper uses a design science approach according to Hevner et al. (2004). The artifact in focus is a software architecture for the implementation of telematicsbased VAA in German healthcare. In order to derive this architecture from the requirements of users, a representative quantitative survey of 117 of 500 registered practitioners of the physician network GO IN e.V. (Dünnebeil et al. 2010a, 2010 b, 2012) was carried out. In addition, qualitative interviews with two general practitioners, two medical specialists, the board of the physician network GO IN e. V., and executives of a health insurance, were conducted. Health insurance and physician network agreed on a contract for integrated care in October 2011 to improve regional care according to performance-related criteria (Audi BKK 2011). In this poll, comprehensive demands on VAA were covered in open questions forming the basis for the architecture to be developed and identifying specific cases with useful potentials. Following the frame described in Sect. 1, an 
identified case is then described and implemented which, through the availability of TI, enabled an improved cooperation in physicians' cooperation as well as new allowance mechanisms on the basis of $\$ 140$ of SGB5 (Fig. 4). For this paper the electronic coordination of appointments and referrals to specialists (eReferral) was chosen as an example. The theoretical contribution of the architecture is, according to Gregor (2006), a theory for the design of medical IS. Thus, the architecture is part of a series of contributions to Software Engineering, examining approaches to systems development in this context. The verification of the eReferral architecture is the prototype of a telematics based VAA, realizing the demands of doctors on the basis of the technical infrastructure of TI, as required by Hevner et al. (2004).

\section{Results of Architecture Specification}

\subsection{Overall Requirements}

From the empirical surveys, the qualitative interviews with the service providers, and an analysis of literature, overall requirement of outstanding significance for VAA were derived. Table 1 shows $10 \mathrm{im}$ portant demands to be covered by the architecture. Reasons for these demands are briefly stated and further explained in the following specification of architectural components.

\subsection{Deduction of VAA-Architecture of TI}

According to OR2, VAA should improve existing processes (Frießem et al. 2005). Aim is the realization of a structured continuous data flow beyond the boundaries of institutions, embedded in healthcare processes. As a starting point, established processes for prescribing, referring, and exchanging information in healthcare were examined and improved. Figure 5 illustrates the organization of a referral process into functional units and layers, to implement the data flow between institutions.

To prevent central storage of patients' data (Dünnebeil et al. 2010b), records are kept in the institutions' local systems and linked via an administrative functional unit (OR1). In a second step of the architectural specification according to OR9, the administrative tasks were separated from the medical ones into two VAA

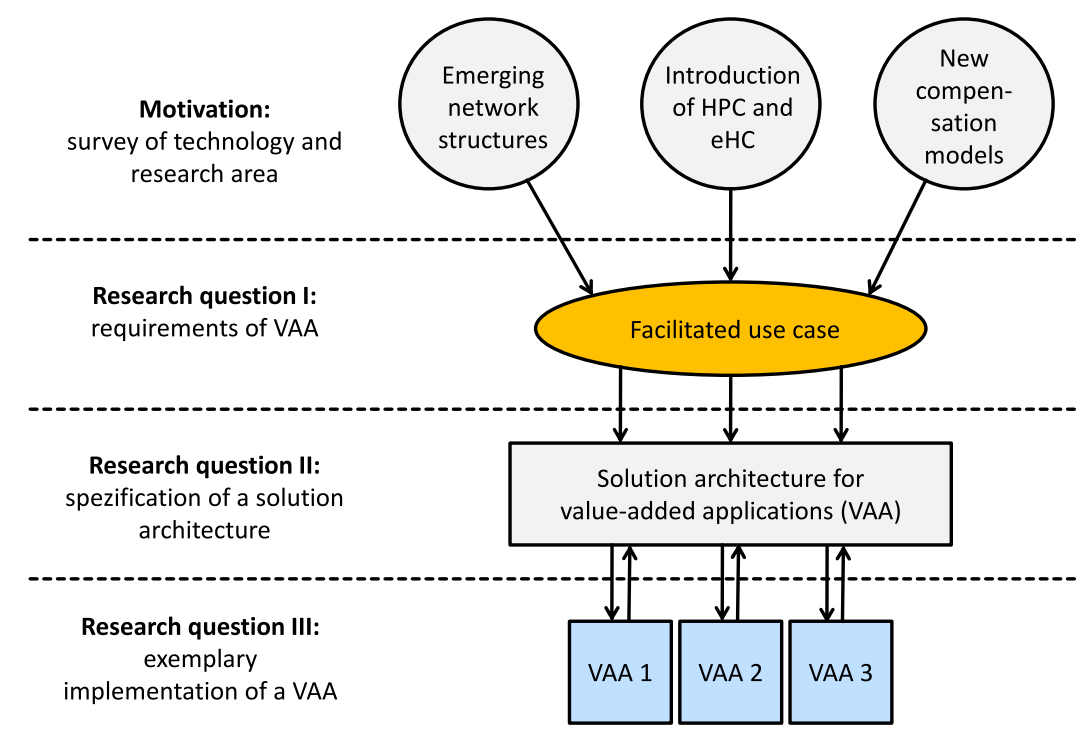

Fig. 4 Research method

(Rohner and Winter 2008). The medical VAA is connected with the primary system to enable the exchange of data (OR4). The intermediation of the patients' data is organized by the patients themselves according to $\$ 291 \mathrm{a}$ of SGB5; patients with limitations regarding the use of the system may delegate these administrative issues to medical assistants (OR8). In a third step, administrative and medical tasks will be organized in functional levels covering well-defined issues of comprehensive requirements. These functional levels provide the basis for a software module of high cohesion. Reuse and standardization of components in healthcare are thus facilitated. The levels have been designed according to existing processes in healthcare and form their digital complement. The printer nowadays serves as an adapter and prints out medical data from the primary system on a standard form. Currently, interoperability in healthcare is made possible by the specification of forms through higher institutions (KBV 2011b), and the signature of a registered doctor insures sufficient authorization. Delivery to unknown recipients (e.g., specialists or pharmacies) is presently handled personally by the patients, mail or fax is used for known recipients. Security (OR7) and controlling (OR10) layers result directly from the requirements; the application layer enables innovative administration and preparation of medical data by the physicians. In the following, these layers are described in detail.

\subsubsection{Adapter Layer}

This layer addresses the question which primary systems are to be included and how this can be implemented. For physicians, the automatic computing of their data is an essential criterion (Dünnebeil et al. 2010a). Double capture of medical data in primary systems and VAA is expressly avoided as otherwise redundant data would have to be collected (OR4). However, the work with primary systems is necessary for most of the service providers in order to settle accounts with the health insurances. The adapter layer establishes the connection between the IS of service providers or patients and VAA. Whereas primary systems for the most part are proprietary and thus closed systems, VAA may be adjusted to regional care processes. Primary systems are used for the collection of medical data, as e.g., medical devices, or for the documentation of treatments and accounting. They are therefore persistent data silos with distributed patients' data, when no comprehensive electronic health record exists. The adapter offers standardized interfaces which can be used by various VAA. Depending on the particular case, data have to be read from the primary system or have to be written into the primary system of the target institution. To that purpose, the adapter uses the interfaces or databases of the primary systems and encapsulates the proprietary data source behind a standard interface. These can be provided, 
Table 1 Overall requirements (OR)

OR 1 VAAs should not store patients' medical data permanently.

The physicians of the practice network $(53 \%)$ are clearly opposed to central storage of patient data. This reinforces a number of previous studies (TKK 2009; Allensbach 2010).

VAAs should, whenever possible, be oriented towards established care processes in order to be able to make use of existing applications and professional processes.

This should help to reduce fear of excessive demands by new IT-supported activities and thereby increase the acceptance of VAAs by improving established processes.

OR 3

The care process modeled in VAAs should be able to replace the existing care process. Parallel execution of both processes is not acceptable.

From the physicians' point of view, digital referrals, prescriptions, hospitalizations or data transfers appear realistic only if they are not carried out in addition to paper based activities.

Interoperability to avoid redundant data capture is necessary in order to avoid manual copying of data into the primary systems.

Daily routine of physicians leaves no time to manually capture lab data or external diagnostic findings. Currently, data from external sources are often only printed and added to the paper files.

OR 5

There is a need to include case-specific and regional requirements of the physician networks in VAAs, independent of the providers of primary systems.

The focal groups of general practitioners, medical specialists, and hospital physicians expressed the wish to define themselves which data should be captured and transmitted in the course of any care process.

Creation and manipulation of medical data objects must be assigned to a person with sufficient level of authorization. Traceability and legal certainty are central concerns in the use of medical records. The wish for transparency and personal accountability was respected here.

VAAs must be built on established and certified security concepts.

This requirement is in accordance with the demand for VAA certification by the federal data privacy authority.

Patients must be able to administer the transfer of their medical data personally, or to delegate this task to a practice employee.

This stresses the protection of patient's rights (\$291a SGB5), the development of patient-centered healthcare (Stewart et al. 2000), and the nondiscrimination of IT-users and other patients.

If possible, medical and administrative tasks should be divisible in separate software modules.

The physicians were receptive towards additional activities that foster quality assurance or improve efficiency. However, they want to delegate tasks that need no medical competencies to assistants.

e.g., as a web service to insure the integration of the primary systems according to the SOA paradigm (Mauro et al. 2009).

\subsubsection{Application Layer}

On this layer, the functionality, which provides the added value, is implemented. These applications offer features not available in the primary systems of the software providers. This is where a large community of designers obtains the chance to introduce innovations into the healthcare system. Thus designers are no longer dependent on the availability and the life cycles of primary sys- tems, and improvements to the quality of care through IT innovations do not remain confined to the producers of a low number of primary systems. Positive developments due to the application of IT systems in treatment support have been proven in many studies (Sarv and Rajiv 2000; Sunyaev and Chornyi 2012; Wu et al. 2006); e.g., by comparing reciprocal effects of medication. The number of medical malpractices could be reduced drastically (Lappé et al. 2004). A case-oriented selection of medical data may reduce the number of double examinations during referrals to a hospital (Sawicki 2005).

\subsubsection{Interoperability Layer}

On this layer, the decision has to be made how to enable distributed VAA to interact with each other. Interoperability denotes the capability of autonomous applications of different origins and heterogenic design to communicate with each other (Wegner 1996). Normally, syntactical interoperability, which implements and guarantees data transfer to the target system and its local computing, is distinguished from semantic interoperability, which governs meaning and use of the data (Ouksel and Sheth 1999). Without a central storage of data and their usage via a standardized interface, a uniform 


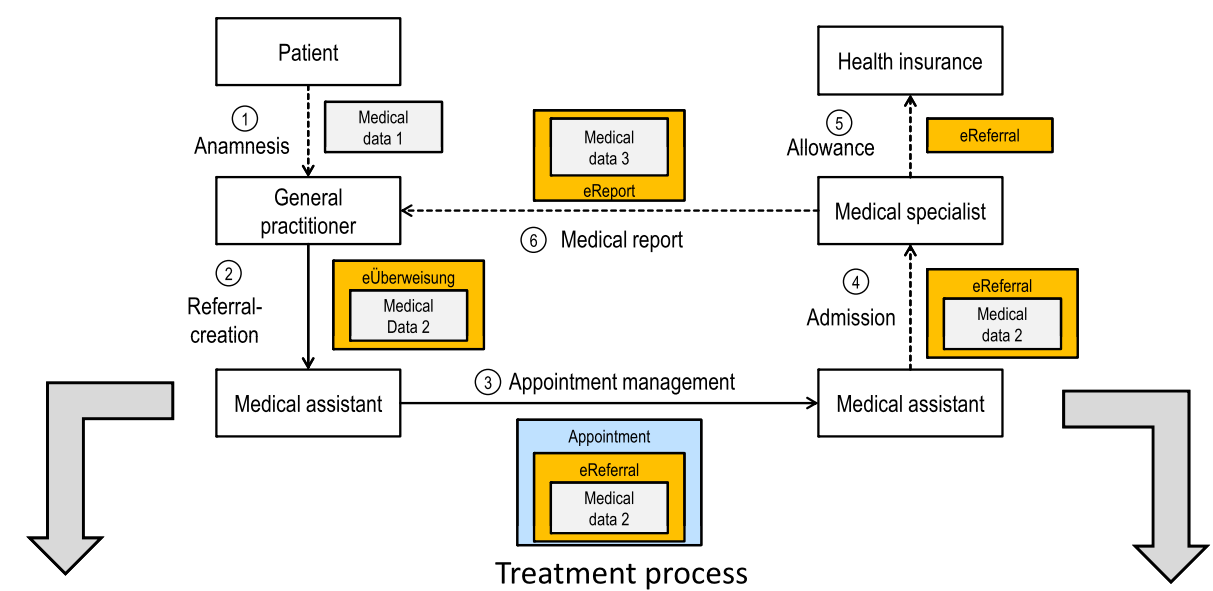

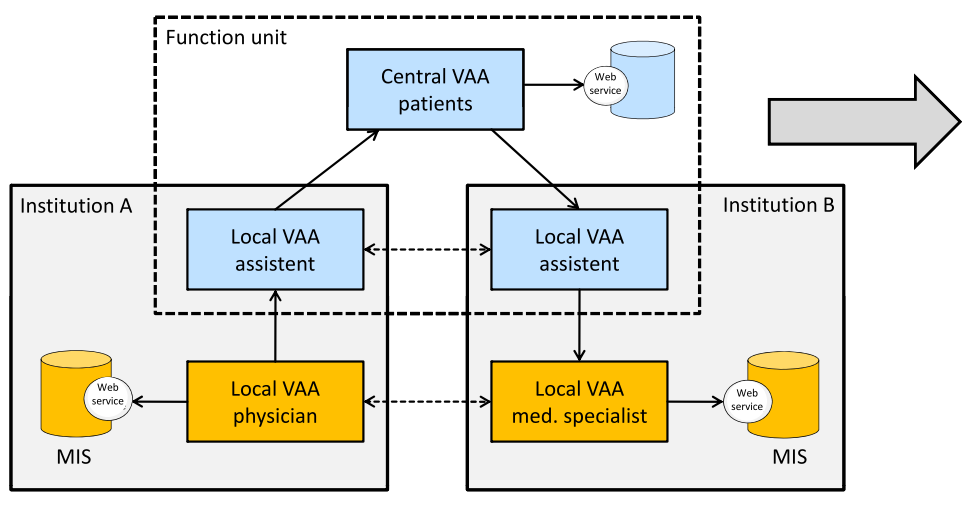

Function units of the stakeholder

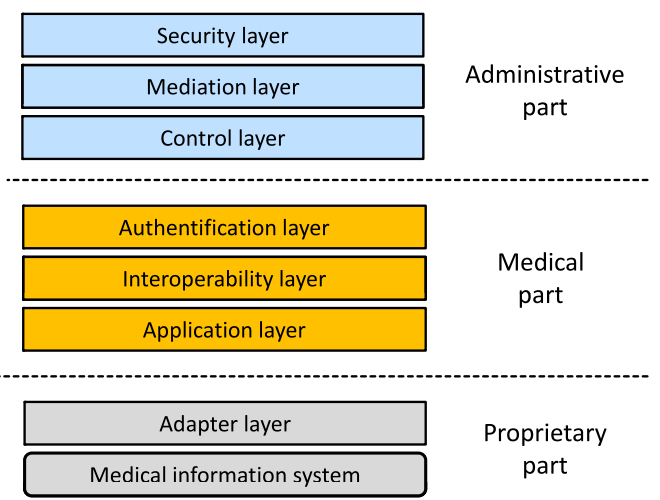

Function layers

Fig. 5 Structural decomposition of the eHealth architecture

exchange format between sender and recipient has to be defined. The sender's system transfers the data into the correct exchange format; the recipient extracts them from here. The topic of interoperability constitutes a large field of research in medical informatics (Pedersen and Hasselbring 2004; Eichelberg and Aden 2005); interoperable exchange formats such as Health Level 7 (HL7) Clinical Document Architecture (CDA), and Continuity of Care Record (CCR) have already been specified (Ferranti et al. 2006). In this way, data can be included in the IS of the recipient and redundant collection is avoided. Possible transfer errors and delays arising from renewed manual collection of the data from forms can be reduced. In the healthcare system various communication and documentation standards already exist, as do comprehensive medical conceptions which make interoperability possible (Pedersen and Hasselbring 2004). With the help of comprising standards, the transfer into the primary systems of the target institution is much easier as no specific adaptation layer is necessary.

\subsubsection{Authorization Layer}

On this layer, the group of caregivers who are entitled to carry out transactions in the VAA have to be defined as well as the technical implementation of these mechanisms (OR6). For healthcare, far reaching concepts have been developed (Chandramouli 2001). In medical processes often mutual obligations arise. Doctors in continuing treatments must be able to trust the documentation of the predecessor's treatments when using it as a basis for decisions without double examinations. Also pharmacies have to rely on the genuineness of a prescription and make sure that the issuer was authorized to write it. Today this is normally guaranteed by the stamp of the institution and the signature of the registered physician. For digital media an electronic signature may be used (Rivest et al. 1978). Often there is no possibility for building personal trust between the parties (Kumbruck 2000), so suitable technical mechanisms have to be provided to verify signatures and refer them to a group of caregivers. For this, an institution is needed which provides and administrates relevant certificates. This institution can also provide passwords, personal identification numbers, or transaction numbers (TAN). Legally binding transactions or documents, like prescriptions, often need a qualified digital signature, whereas other documents, such as physicians' letters, may be sent without signature.

\subsubsection{Control Layer}

On this layer, it is necessary to implement the option to gather and evaluate controlling data from care processes to guarantee OR10. For the accounting of services from integrated care contracts according to $\$ 140$ SGB5, contract partners can include the particular treatments provided by a physician and thus compensate them outside the regular payment 
volume. In this way, each case generates a well-defined set of data which can be used on the management level for controlling and quality security. These data may also facilitate improvements in the medical quality of treatments, as they gain access to recommendations of evidence based medicine, grounded on real data (Sackett et al. 1996). In data warehouses (Stolba and Tjoa 2006), patients' data can be prepared for this purpose and sufficiently aggregated and made anonymous to fulfill OR1 (Sweeney 1997). To provide data from the network may also be of importance for a care process. A choice of preferred suppliers or prompt treatment dates can be provided in addition to the medical document, in order to direct the later transmittance to further service providers according to economic or organizational considerations. A discretionary and comprehensive collection and evaluation of data from VAA, as often occurs in mobile communication and Internet applications (O’Brien 2010), must be prevented. The design of a controlling layer has to follow a structured approach for Privacy Engineering (Kaletsch and Sunyaev 2011).

\subsubsection{Mediation Layer}

On this layer, the challenge has to be addressed, which recipients shall receive the data and how this mediation can be implemented technically. Currently patients are given a prescription or a medical letter and then hand these documents over personally. Thus a prescription for medication can be filled in the closest pharmacy, a date with a specialist or a taxi ride to a specialist can be arranged by phone. A digital mediation of medical data, e.g., an electronic prescription of a drug or of orthopedic means, follows a fixed procedure set beforehand according to economic or medical aspects. Thus the process follows objective rules. Provisions for an objective mediation can be guaranteed in advance on the controlling level. Then precise orders can be placed with the help of the network's information concerning the best price or best conditions of a medication, for example. If a doctor has issued a prescription for a medical adjuvant, this can be used in the supply store either with the best price, or the fastest delivery, or the best quality. Appointments can be organized according to objective rules as well. E.g., an appointment with a specialist can automatically be reserved either within a distance of ten kilometers, or with a physician who is a partner of a particular contract, or with one who has a good rating.

\subsubsection{Protection Layer}

Protection and privacy of medical data is an aspect of outstanding importance (Rindfleisch 1997; Stanford 2002; Sunyaev and Pflug 2012). In consideration of this fact, the question has to be addressed, which protection standards are to be used and which mechanisms are chosen for their implementation. Both supporters and opponents of telematics favor obligatory and comprehensive standards in the application of telematics (Dünnebeil et al. 2010a). German law explicitly regulates access, audition and codification of telematics applications in the SGB (BRD 2004a). In addition, the American "Health Insurance Portability and Accountability Act (HIPAA)" precisely regulates the handling of digital medical data, including technical aspects besides the administrative and physical protection of medical data (Mercuri 2004). High fines and imprisonment are imposed for offenses against HIPAA. Authorities have to agree on a protection level for VAA of TI which complies with legal regulations. This provides a balance between usability and protection and implements this on the protection layer using suitable measures.

\section{Exemplary Implementation of a VAA}

To illustrate the architecture, a specific VAA supporting an application scenario was implemented. Based on the abstract architecture, a case specific architecture was designed for this scenario. In discussions with the involved practice partners the eReferral was identified as a case with high potential.

\subsection{Functional Requirements}

A referral to a specialist entitles a patient in German healthcare for treatment by a specialist. It is issued by a registered general practitioner. In the traditional system, the referral form is an undirected entitlement to obtain a specialist's services. It is handed over to the specialist's practice by the patient after making an appointment. This means that patients implicitly choose the recipient of the medical documentation. In this way, the undirected communication becomes a directed one. The VAA described here attempts to combine the processes of making an appointment with the referral and the communication of medical data. Thus traditional processes are combined, digitalized, improved, and simplified. For this purpose the processes of referral and appointment are combined. The added value of the VAA is to be found in the digital authorization of the patient, the integrated electronic appointment management, and the specific selection and communication of digital medical information.

To offer the reservation of specialists' appointments via a central platform aims for a relief of patients and assistants in practices, as the arrangement of prompt appointments often requires extensive communication efforts. Detecting dates favorable in time or location could be simplified by an adequate specification in the system. EReferrals should be issued by general practitioners and be made legally binding by a qualified electronic signature. Furthermore, general practitioners are enabled to transfer medical data from their MIS into the digital referral form without having to do this manually, in order to automatically make them available for further use by the specialist. Functional requirements from the phase of conception are shown in the online Appendix. Architectural layers of VAA have been instantiated in the software design for the eReferral. To this purpose, the respective components were specified and implemented to illustrate their suitability for the design. Figure 6 shows the specific architecture of the eReferral.

\subsection{Adapter for the Medical Information System}

The MIS-adapter layer guarantees access to the source systems of general practitioners and the target systems of the specialists in case of an eReferral. Data transferred into VAA can be called upon via interfaces of the application components of the primary systems. To make them automatically legible, data from primary systems which are often unstructured have to be coded syntactically and semantically to exclude ambiguities. For the standardization of diagnoses the terminology system International Classification of Diseases Version 10 (ICD-10) was used, for medication the Pharmaceutical Central 


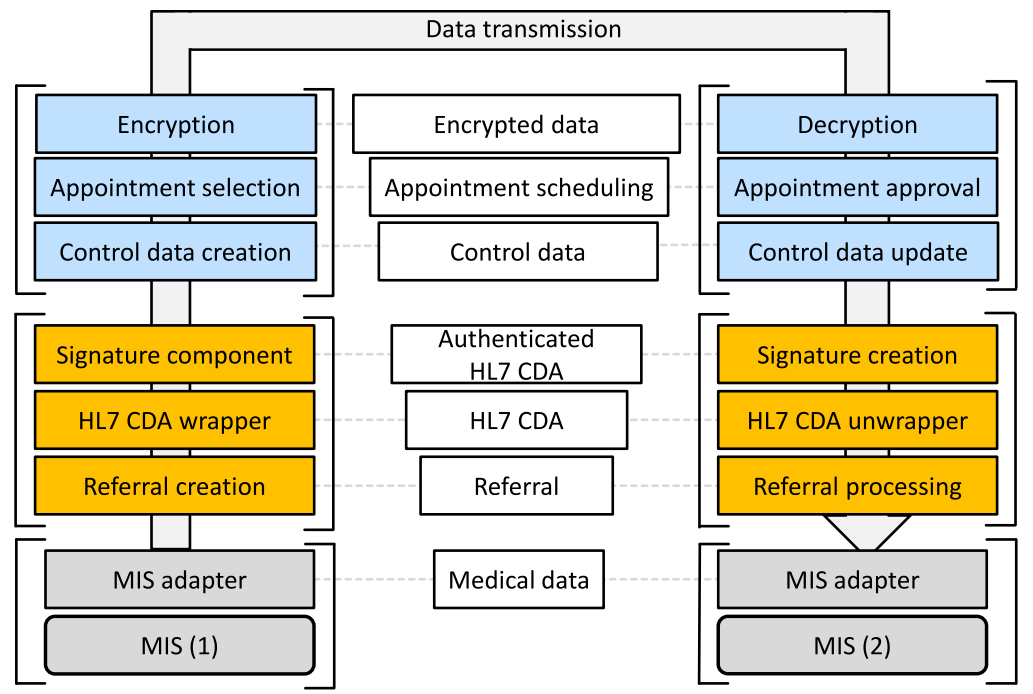

Fig. 6 Functional architecture of eReferral

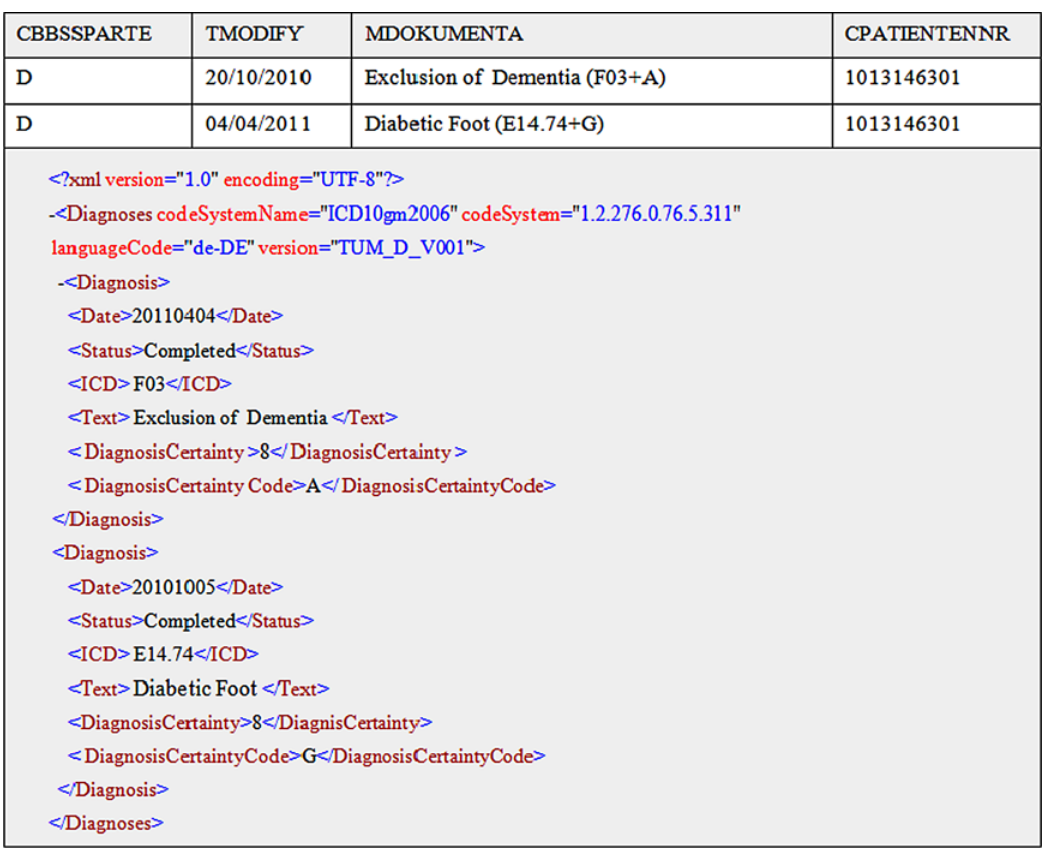

Fig. 7 MIS data structure and AIS adapter output

Number $(\mathrm{PZN})$. The adapter was implemented as a web service to allow uniform access to the systems. Figure 7 illustrates the access to data of the source system and the responses of the XML web services. In this component, problems are caused by the inconsistent coding and storage of medical data in the primary systems. Access to the data is possible only after a thorough analysis of the data storage. Transfer of mostly textually coded attributes into comprehensive terminology systems proves difficult, as of- ten an automatic allocation is not possible. Thus findings from the laboratory could be read in the original only, as a preparation of measurement units and values was impossible due to inadequate data.

\subsection{Generating a Referral}

The component for the generation of a referral uses the adapter to gain access to the primary systems' data and a connector for access to the eHC's data. When generating a referral, this allows doctors to select, sort, and enhance data for the recipient according to the case. Up to date, a referral to a specialist contains medical information, which the general practitioner can print or write on the form. Whereas the paper based referral cannot be read by machines and is limited to A5 format, the advantages of electronic data processing can be utilized in the eReferral. The fields of the eReferral build a discretionary superset of the ones in currently used paper forms. The selection of medical data according to case related criteria can thus be provided with various digital elements to describe and pass on the medical records of the patient adequately (Shekelle et al. 2006). A web application was programmed in ASP.NET; the desktop was customized to the paper form and fitted to the requirements of the doctors' collective. Tools for the selection of diagnoses and medications, like code completions and patterns, were implemented. An interactive examination of the drugs in the communicated data via an external web service of PZN was put to the test. Central trainings for all users of the practice network as well as simple adjustments and maintenance are possible, due to the standardization of the software. Figure 8 illustrates the user interface of the eReferral using the referral data of a patient with diabetes mellitus type 2 .

\subsection{HL7 CDA Wrapper}

The interoperability component uses the interfaces of the application components to transform data, which were prepared according to case related criteria, into an interoperable format. In the case of an eReferral, the recipient's MIS has to compute the data free from errors and the user of the IS has to interpret the contents according to the intentions of the sender. To this purpose, a standardized referral form was designed on the basis of the interoperable exchange format HL7 CDA, which is based on the electronic medical letter of the association of producers of IT-solutions for healthcare (VHitG) (VHitG 2006). Master data of doctor and patient are transferred into the HL7 header of the eReferral, which can be reused for additional digital forms. Medical data prepared according to ICD and PZN are given a LOINC header and transferred as CDA level 3 components to the CDA body of the document (VHitG 


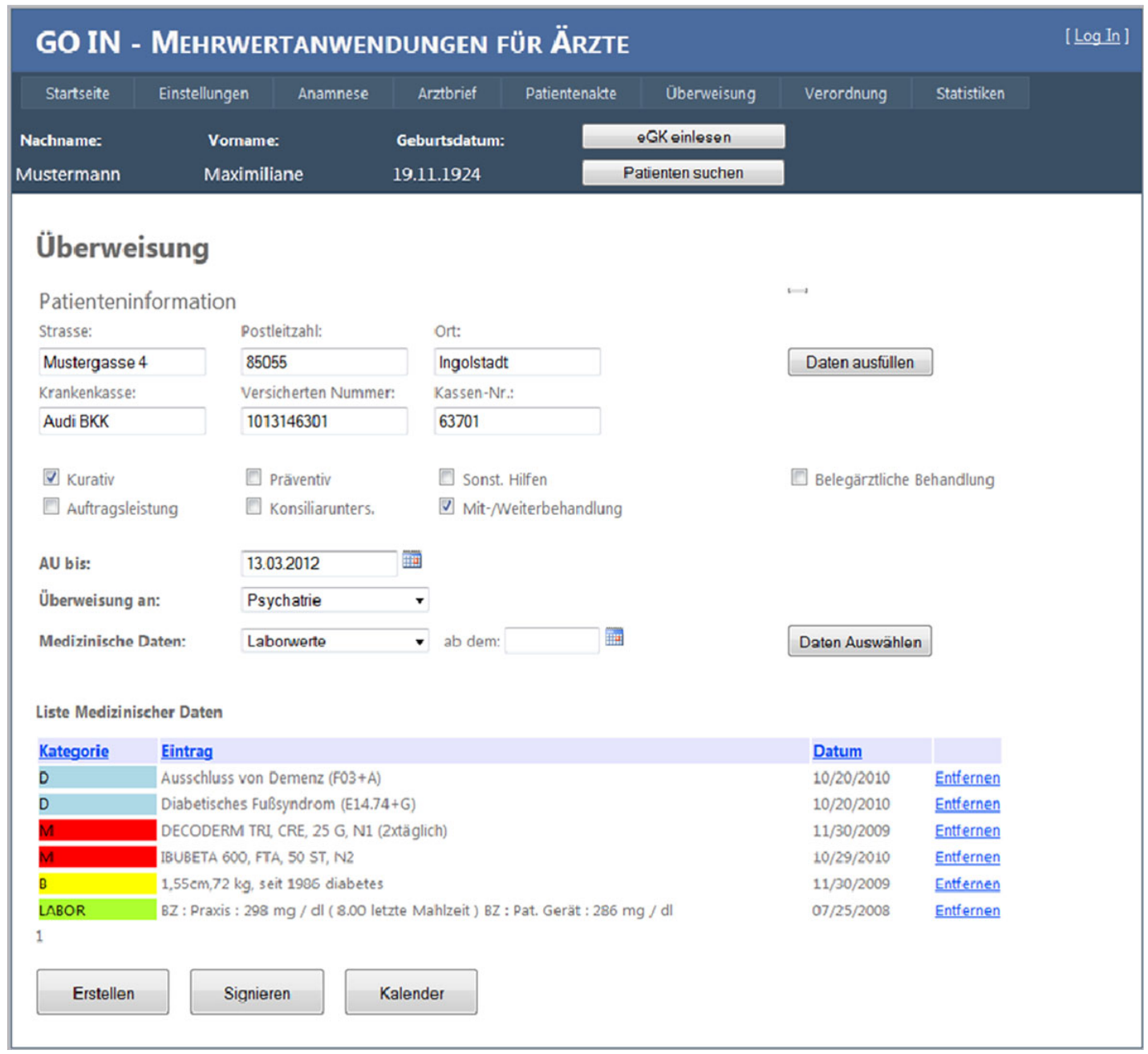

Fig. 8 The eReferral

2006). All other data elements were prepared in level 2 components; a comprehensive automatic legibility for these data is not possible due to the adapter. The interfaces for the components were labeled in a way allowing them to be adapted also for accessing CCR records or gematik prescriptions. A comprehensive style sheet ensures an identical visual impression for all users. Further elements can be added, which currently are not allotted or usable on paper forms, e.g., anamnesis or image documents (Fig. 9).

\subsection{Signature Component}

To make sure that the user of VAA is authorized to issue a referral, an electronic signature with a healthcare identification (so called Health Professional Card, HPC) has to be installed before the transaction can be processed. The signature component accesses the interoper- ability layer to obtain a HL7 CDA document. Then the private key of the general practitioner is read from the HPC, determining sufficient authorization by the doctor entering his PIN (gematik 2009c). The qualified electronic signature is realized through the connector interface signDocument, the signature component creates a TAN, allowing patients and assistants to reserve an appointment with the relevant specialists' group. Following this step, document and TAN are stored in an exchange file, which can be read by the local component of the appointment manager. On the recipient's side, the signature can be verified against the certificate of the general practitioner to guarantee genuineness (gematik 2009b). The component mainly uses web services of gematik and can therefore be used for additional digital forms in other VAA.

\subsection{Control Component}

The practice network's aim is to reduce the waiting times for specialists' appointments. Free dates for a specialist's meeting will be shown in the net centrally if approved beforehand by the doctors. Thus patients and assistants can outline available dates according to criteria like time, distance, or kind of treatment. This should enable a best possible distribution of available appointments to inquiring patients and minimize telephone coordination. To this purpose, the web service createAppointment was developed, which creates new appointment slots using the parameters timespan, kind of treatment, and master data of a doctor. Free slots can be called up via the interface getAppointment and are then shown in the calendar component or a schedule. Optional limitations can be made. Local distance, time slots, kind of treatment, and master data 


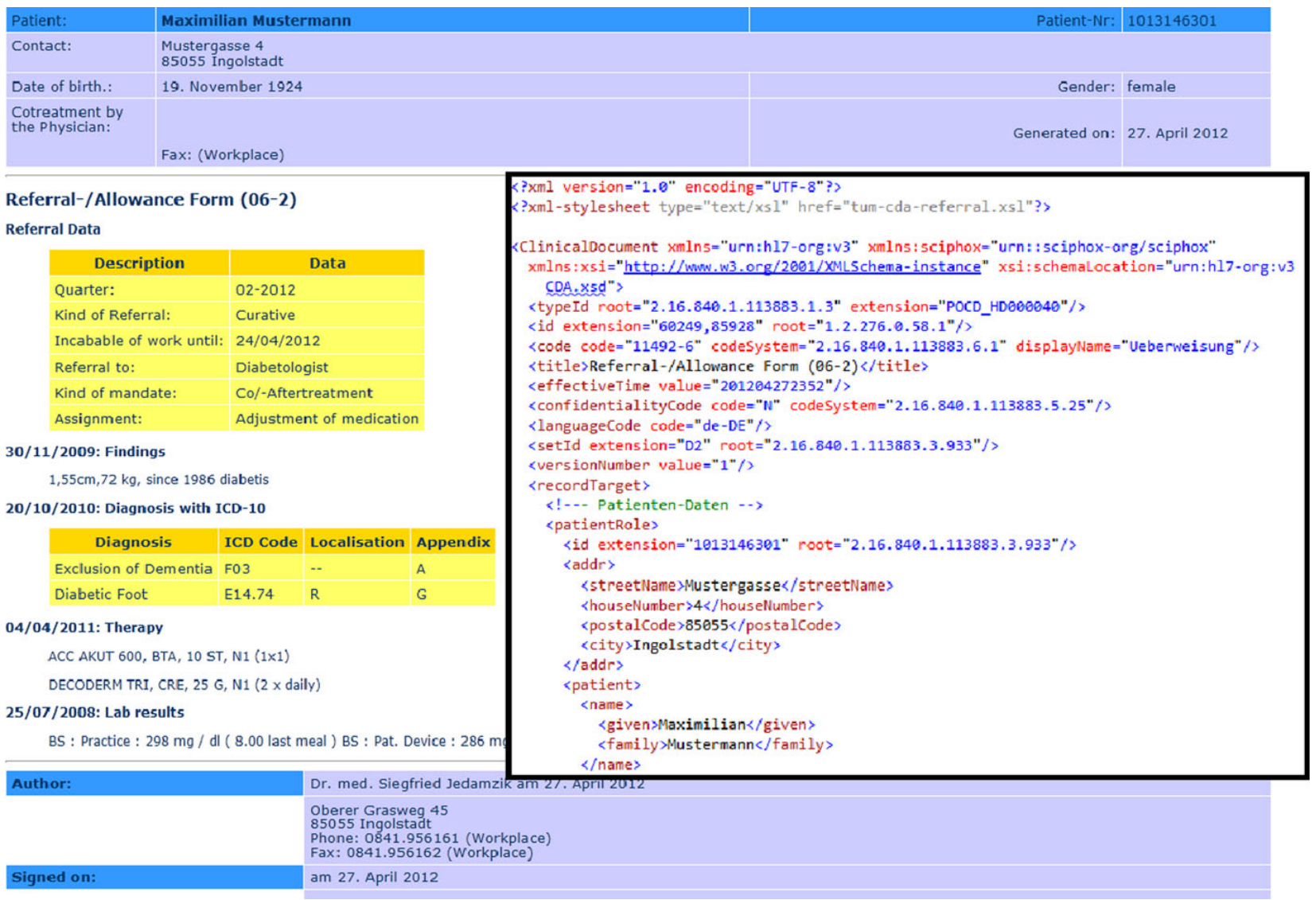

Fig. 9 HL7 CDA view of the eReferral

of the doctor are possible parameters. A visualization is used when transmitting eReferrals, e.g., when looking for an appointment within the next seven days. The controlling component has the function of a user interface for inquiries and automatically provides parameters, if the calendar of a doctor or a time slot and the kind of treatment is stated by the user (Fig. 10).

\subsection{Selection of Appointments}

The date component calls up the controlling component to obtain free time slots. The patients' component runs on the server of the practice network and is available in the Internet. In the local practice applications, appointments of the own practice can be fixed, released, and reserved. A release contains the specialist group, the kind of treatment, the available time slot, and the duration of the particular appointment. After releasing a date, it is synchronized with the central appointment service. By entering a TAN, all available dates of a particular group of specialists can accessed and reserved in the central service. This step can be performed both by the practice assistants on the local VAA and by the patient himself on the central VAA. The reservation of a date blocks the TAN. Cancellation of an appointment by either the patient or the practice assistants re-activates the TAN, if cancellation is carried out within the same quarter.

\subsection{Encryption}

To ensure adequate security of the communication, a hybrid encryption of the referral performed by the connector was chosen (gematik 2009b). After the reservation of the date, the certificate of the doctor continuing the treatment is loaded into the VAA, ciphered with the referral and stored temporarily in the exchange service of the appointment server, until called on by the local VAA of the target doctor. In addition, an appointment record is filed and stored on the central server, containing only the agreed date, the kind of specialist, and a patient's pseudonym. This pseudonym is completed with the personal data from the eHC on the local system of the target doctor when the practice is actually visited. Only then can the specialist decipher the eReferral with his HPC and make use of the contents. In this way, appointment data cannot be related to real world persons in case of attack by hackers (Dünnebeil et al. 2011).

\section{Implications}

The need for integrated and regionally adapted treatment processes on the one side and the rejection of central patients' files in German healthcare on the other necessitates the development of divided software applications. Often the adoption of comprising processes based on existing IS is impossible due to the huge diversity of proprietary and closed primary systems. Customized processes, as shown in the case of the eReferral, can be structurally designed and implemented with the help of distributed VAA. Here, basic services of TI can be used for important functions. In the future, designers 

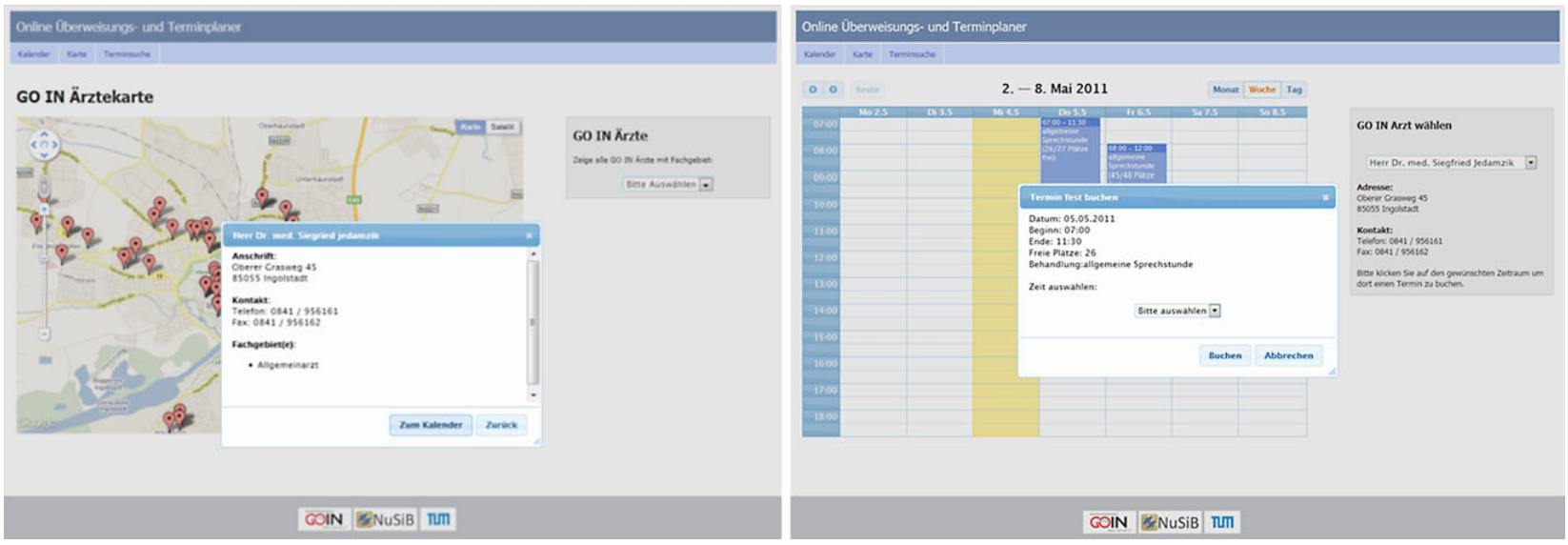

Fig. 10 Net data selection and appointment scheduling

can implement such VAA in a structured way following the requirements of the introduced architecture. On each layer, requirements and standards can be defined considering important criteria of medical applications. Established components can be reused in similar cases to reduce design efforts. In the long run, a substantial service ecosystem (Barros and Dumas 2006) may emerge around the eHC, using established conceptions of information engineering. The development in mobile communication can be seen as a reference, even though aspects of security and protection have a higher significance in healthcare. The infrastructure of telematics must not necessarily be used extensively in VAA; in many areas, however, it acts as useful support for requirements of numerous service providers. A lasting central storage of patients' data is not necessary with telematics applications if an approach using distributed VAA is chosen. Usability is thus given priority, as important security aspects have already found consideration in the design of the architecture.

This contribution sets first corner points of a reference architecture for VAA of TI; still needed, however, is an analysis of additional medical treatment processes to include more of the respective requirements. An evaluation and iterative refinement of reference architecture can be effected through applications in the field, if progress in TI continues adequately. Furthermore, a variety of technical and organizational challenges arises with the implementation of particular architectural layers, which are in need of detailed scientific reflection. This article could only partly deal with these aspects, as a general view of VAA of TI was the main issue. The focus was on a comprehensive introduction and motivation of the topic, the collection and structuring of basic requirements and the illustration of an exemplary application. Thus, the basis for a more differentiated discussion of healthcare telematics could be initiated by showing conceptions which exceed special applications known so far.

\subsection{Theoretical Contribution}

The contribution collects and structures important requirements of healthcare in a comprising architecture for VAA. The following aspects: inclusion of existing systems, interoperability, authorization, controlling, communication, and protection, already examined in former architectural approaches, are brought together and interrelated with another. In this way, an abstract design theory for distributed VAA in healthcare is generated. The architecture falls in line with contributions on software engineering which in this context offer approaches for systems development in different domains, when inclusion of existing systems, legally binding signatures, interoperability, division of operational and controlling data, and objectified and encrypted mediation are of importance. The verification of the architecture of the VAA for eReferrals is also an early prototype for telematics applications considering requirements on the basis of the technical infrastructure of German healthcare telematics, as requested by Hevner et al. (2004) for new technologies.

\subsection{Practical Implications}

With this contribution, software designers receive a basis for discussion of im- portant architectural judgments, allowing concrete software design decisions. Usability and treatment potentials can be implemented on the basis of a theoretically founded architecture, whose key aspects are directly derived from the requirements of the caregivers in the field. Thus the call for more integration of the users in telematics is met. Furthermore, the development of VAA should increasingly become the focus of activities of authorities and gematik to indicate the potentials of eHC beyond the much discussed special applications. The design of the eReferral turned out to be of great interest to the participating physicians, as currently they have to put a lot of resources into the coordination of appointments. To show that the introduction of the eHC is necessary for such processes can improve the image of healthcare telematics considerably. Additional applications on the basis of the architectural model were discussed and implemented but not shown in this article (compare Dünnebeil et al. 2011). The collection of vital parameters by patients and their communication to registered doctors in a framework of monitoring programs was researched; a structured digital communication between doctors and pharmacists could be implemented in a VAA for prescription management, following the presented reference architecture. Substantial potentials for the reuse of existing modules and a well-defined structure of programs could be recognized.

\section{References}

Allensbach (2010) ifD-Umfrage 5283. Der Einsatz von Telematik und Telemedizin im Gesundheitswesen. Allensbach 
Arsanjani A, Allam A (2006) Service-oriented modeling and architecture for realization of an SOA. In: IEEE international conference on services computing, Chicago, p 521

Audi BKK (2011) Audi BKK und das Praxisnetz GO IN unterzeichnen neuen Versorgungsvertrag - Audi BKK. http://www.audibkk. de/Presse-Archiv.38+M5022316c79a.0. html. Accessed 2011-12-13

Barros AP, Dumas M (2006) The rise of web service ecosystems. IT Professional 8(5):31 37

Bernnat R (2006) Kosten-Nutzen-Analyse der Einrichtung einer Telematik-Infrastruktur im deutschen Gesundheitswesen. Booz Allen Hamilton $\mathrm{GmbH}$, Düsseldorf

BITKOM (2009) Position der Leistungserbringer zur Neuausrichtung der Einführung eGK/Telematikinfrastruktur (Gesundheitskarte) - BITKOM. http://www.bitkom.org/ de/themen/37207_62030.aspx. Accessed 2011-12-13

Blobel B (2004) Authorisation and access control for electronic health record systems. International Journal of Medical Informatics 73(3):251-257

BMG (2005) The German eHealth strategy (target and strategy, concept, legal framework, activities/roll-out plan, costs and return of investment. European perspective). Berlin

BRD (2004a) Sozialgesetzbuch (SGB) Fünftes Buch, Gesetzliche Krankenversicherung, $\S 291 \mathrm{a}$

BRD (2004b) Sozialgesetzbuch (SGB) Fünftes Buch, Gesetzliche Krankenversicherung $\S 140 a$

Buschmann F, Meunier R, Rohnert H, Sommerlad P, Stal M (1996) Pattern-oriented software architecture. Wiley, New York

Chandramouli R (2001) A framework for multiple authorization types in a healthcare application system. In: Proc 17th annual computer sec appl conf, Los Alamitos, p 137

Dehling T, Sunyaev A (2012) Information security of patient-centered services utilising the German nationwide health information technology infrastructure. In: 3rd USENIX workshop on health security and privacy (HealthSec 2012), co-located with the 21 st USENIX security symposium (USENIX security '12), Bellevue https://www.usenix.org/conference/ healthsec12/information-security-patientcentered-services-utilising-germannationwide. Accessed 2012-10-16

Dern G (2009) Management von IT-Architekturen: Leitlinien für die Ausrichtung, Planung und Gestaltung von Informationssystemen. Vieweg + Teubner, Wiesbaden

Dijkstra EW (1968) The structure of the THEmultiprogramming system. Communications ot the ACM 11(5):341-346

Dinh M, Chu M (2006) Evolution of health information management and information technology in emergency medicine. Emergency Medicine Australasia 18(3):289-294

Dünnebeil S, Sunyaev A, Blohm I, Leimeister JM, Krcmar H (2010a) Do German physicians want electronic health services? A characterization of potential adopters and rejecters in German ambulatory care. In: 3rd international conf on health informatics 2010, Valencia, pp 202-209

Dünnebeil S, Sunyaev A, Leimeister JM Krcmar H (2010b) Strategies for development and adoption of EHR in German ambulatory care. In: 4th IEEE int conference on pervasive computing technologies for healthcare, Munich. doi:10.4108/ ICST.PERVASIVEHEALTH2010.8887
Dünnebeil S, Kaletsch A, Jedamzik S, Sunyaev A, Leimeister JM, Krcmar H (2011) Prozessdigitalisierung durch Mehrwertanwendungen der eGK am Beispiel der elektronischen Überweisung. In: PerspeGKtive 2011 - Innovative und sichere Informationstechnologie für das Gesundheitswesen von morgen, Darmstadt

Dünnebeil S, Sunyaev A, Blohm I, Leimeister JM, Krcmar H (2012) Determinants of physicians' technology acceptance for ehealth in ambulatory care. International Journal of Medical Informatics 81(11):746760. doi:10.1016/j.ijmedinf.2012.02.002

Eichelberg $M$, Aden T, Riesmeier Jr, Dogac A, Laleci GB (2005) A survey and analysis of electronic healthcare record standards. ACM Computing Surveys 37(4):277-315

Fayn J, Ghedira C, Telisson D, Atoui H, Placide J, Simon-Chautemps L, Chevalier P, Rubel P (2003) Towards new integrated information and communication infrastructures in e-health. Examples from cardiology. In: Computers in cardiology, Lyon, pp 113116

Ferranti JM, Musser RC, Kawamoto K, Hammond WE (2006) The clinical document architecture and the continuity of care record: a critical analysis. Journal of the American Medical Informatics Association 13(3):245-252

Fettke P, Loos P (2002) Methoden zur Wiederverwendung von Referenzmodellen Übersicht und Taxonomie. In: Multikonferenz Wirtschaftsinformatik, Nürnberg, pp 9-33

Fraunhofer (2005) Spezifikation der Lösungsarchitektur zur Umsetzung der Anwendungen der elektronischen Gesundheitskarte. Fraunhofer ISST, IAO, SIT, FuE-Projekt "Lösungsarchitektur", Berlin

Frießem P, Kalmring D, Reichelt P (2005) Lösungsarchitektur für die Einführung der elektronischen Gesundheitskarte und der auf ihr basierenden Anwendungen. WIRTSCHAFTSINFORMATIK 47(3):180-186

gematik (2009a) Einführung der Gesundheitskarte - Gesamtarchitektur. Berlin

gematik (2009b) Einführung der Gesundheitskarte - Konnektorspezifikation. Berlin gematik (2009c) Einführung der Gesundheitskarte - Übergreifendes Sicherheitskonzept. Berlin

gematik (2012) Anwendungen der eGK. http://www.gematik.de/cms/de/egk_2/ anwendungen/anwendungen_1.jsp. Accessed 2012-05-15

Gregor S (2006) The nature of theory in information systems. MIS Quarterly 30(3):611642

Gritzalis D, Lambrinoudakis C (2004) A security architecture for interconnecting health information systems. International Journal of Medical Informatics 73(3):305-309

Hasselbring W (2000) Information system integration. Communications of the ACM 43(6):32-38

Hevner A, March S, Park J (2004) Design science in information systems research. Management Information Systems Quarterly 28(1):75-105

Holzer A, Ondrus J (2011) Mobile application market: a developer's perspective. Telematics and Informatics 28(1):22-31

Hornung G, Goetz CFJ, Goldschmidt AJW (2005) Die künftige Telematik-Rahmenarchitektur im Gesundheitswesen. Recht Technologie, Infrastruktur und Ökonomie. WIRTSCHAFTSINFORMATIK 47(3):171-179

Jacobs K, Schulze S (2004) Wettbewerbsperspektiven integrierter Versorgung

\section{Abstract}

Sebastian Dünnebeil, Ali Sunyaev Jan Marco Leimeister, Helmut Krcmar

\section{Modular Architecture of Value-Added Applications for German Healthcare Telematics}

Value-added applications of the German healthcare telematics aim at patient orientation as well as quality and efficiency improvements in the healthcare sector. Telematics services can be utilized in many ways, e.g., to guarantee security standards and interoperability. The electronic health card is merely one example. The design science oriented article presents the development and evaluation of a software architecture for value-added applications. In order to achieve better user acceptance, the architectural requirements were derived directly from the caregivers. The architecture is illustrated and evaluated by the example of electronic referral management. Typical functional units of medical processes are modeled in seven layers. The instantiation shows a structured application with high security standards which enables interoperability between heterogeneous existing systems and extensive control by physicians' cooperatives. The architecture offers, for the first time in German healthcare, the opportunity to safely and reliably specify and develop a variety of value-added applications which can be provided via the telematics infrastructure.

Keywords: Electronic health card, Healthcare telematics, Value-added applications, Value-added services, Software architecture, Design research 
in der gesetzlichen Krankenversicherung. Gesundheitsökonomische Beiträge 44:89-110

Kaletsch A, Sunyaev A (2011) Privacy engineering: personal health records in cloud computing environments. In: Proc 32th international conference on information systems, Shanghai, Paper 2

KBV (2010) Online-Anbindung. http://www. kbv.de/12629.html. Accessed 2012-01-12

KBV (2011a) Installationsstatistik - Systeme. In: http://www.kbv.de/ita/4299.html. Accessed 2012-01-12

KBV (2011b) Änderung der Vereinbarung über Vordrucke für die vertragsärztliche Versorgung. Deutsches Ärzteblatt 108(50): 2739

Kirn S (2005) Gesundheitsinformatik Informationssysteme für das Gesundheitswesen von morgen. WIRTSCHAFTSINFORMATIK 47(3):165-166

Köbler F, Fähling J, Krcmar H (2010) IT governance and types of IT decision makers in German hospitals - an empirical study among IT decision makers. Business and Information Systems Engineering 2(6):359370

Kumbruck C (oJ) Digitale Signaturen und Vertrauen. https://eldorado.tu-dortmund. de/handle/2003/28314. Accessed 2012-03-

Lappé JM, Muhlestein JB, Lappé DL, Badger RS (2004) Improvements in 1-year cardiovascular clinical outcomes associated with a hospital-based discharge medication program. Annals of Internal Medicine 141(6):446-453

Marsic I (2001) An architecture for heterogeneous groupware applications. In: Int conf software engineering 2001, Washington, pp 475-484

Mauro C, Sunyaev A, Leimeister J, Krcmar H (2009) Serviceorientierte Integration Medizinischer Geräte - Eine State of the Art Analyse. In: Proc Wirtschaftsinformatik 2009, Wien, pp 119-128

Mercuri RT (2004) The HIPAA-potamus in healthcare data security. Communications of the ACM 47(7):25-28

Mertens P (2012) Schwierigkeiten mit ITProjekten der Öffentlichen Verwaltung - Neuere Entwicklungen InformatikSpektrum 32(1):42-49. doi:10.1007/ s00287-008-0310-9

Neuhaus J, Deiters W, Wiedeler M (2006) Mehrwertdienste im Umfeld der elektronischen Gesundheitskarte. InformatikSpektrum 29(5):332-340

O'Brien KJ (2010) Google data admission angers European officials. The New York Times

Ouksel AM, Sheth A (1999) Semantic interoperability in global information systems. ACM SIGMOD Record 28(1):5-12. doi:10.1145/309844.309849

Papazoglou MP (2003) Service-oriented computing: concepts, characteristics and direc- tions. In: Fourth int conf on web information systems engineering, Rome, pp 3-12

Pedersen S, Hasselbring W (2004) Interoperabilitat für Informationssysteme im Gesundheitswesen auf Basis medizinischer Standards. Informatik - Forschung und Entwicklung 18(3-4):174-188

Riedl B, Grascher V, Neubauer T (2008) A secure e-health architecture based on the appliance of pseudonymization. Journal of Software 3(2):23-32

Rindfleisch TC (1997) Privacy, information technology, and healthcare. Communications of the ACM 40(8):92-100

Rivest RL, Shamir A, Adleman L (1978) A method for obtaining digital signatures and public-key cryptosystems. Communications of the ACM 21(2):120-126

Rohner P, Winter R (2008) Was kann die Wirtschaftsinformatik dazu beitragen, e-Health voran zu bringen? WIRTSCHAFTSINFORMATIK 50(4):330-334

Sackett DL, Rosenberg WMC, Gray JAM, Haynes RB, Richardson WS (1996) Evidence based medicine: what it is and what it isn't. British Medical Journal 312(7023):71-72

Sarv D, Rajiv K (2000) Information technology payoff in the health-care industry: longitudinal study. Journal Management Information Systems 16(4):41

Sawicki P (2005) Qualität der Gesundheitsversorgung in Deutschland. Medizinische Klinik 100(11):755-768. doi:10.1007/s00063 005-1105-2

Schweiger A, Sunyaev A, Leimeister JM Krcmar H (2007) Information systems and healthcare XX: toward seamless healthcare with software agents. Communications of the AIS 19(1):692-710

Shaw M, Garlan D (1996) Software architec ture: perspectives on an emerging discipline. Prentice Hall, New York

Shekelle P, Morton SC, Keeler EB (2006) Evidence report - technology assessment. In: Costs and benefits of health information technology

Silber S (2006) Argumente für die Integrierte Versorgung als Regelversorgung in de Kardiologie. Clinical Research in Cardiology 95(80):ii37-ii40

Stanford V (2002) Pervasive healthcare applications face tough security challenges. IEEE Pervasive Computing 1(2):8-12

Stewart M, Brown JB, Donner A, McWhinney IR, Oates J, Weston WW, Jordan J (2000) The impact of patient-centered care on outcomes. Journal of Family Practice 49(9):796-804

Stolba N, Tjoa A (2006) The Relevance of Data Warehousing and Data Mining in the Field of Evidence-based Medicine to Support Healthcare Decision Making. International Journal of Computer Systems Science and Engineering 3(3):143-148

Sunyaev A, Chornyi D (2012) Supporting chronic disease care quality: design and implementation of a health service and its integration with electronic health records. ACM Journal of Data and Information Quality 3(2):3:1-3:21. doi:10.1145/2184442.2184443

Sunyaev A, Pflug J (2012) Risk evaluation and security analysis of the clinical area within the German health information infrastructure. Health and Technology 2(2):123-135. doi:10.1007/s12553-012-0016-5

Sweeney L (1997) Guaranteeing anonymity when sharing medical data, the Datafly system. In: Proc AMIA annual fall symposium, Nashville, pp 51-55

Szyperski C, Gruntz D, Murer S (2002) Component software: beyond object-oriented programming. Pearson Education, Upper Saddle River

TKK (2009) 1, Branchenbarometer E-Health F.A.Z.-Institut für Management-, Markt- und Medieninformation, Frankfurt

Tsai WT, Fan C, Chen Y, Paul R, Chung $J-Y$ (2006) Architecture classification for SOA-based applications. In: Proc 9th IEEE international symposium on object and component-oriented real-time distributed computing, Gyeongju, pp 295-302

Tsiknakis M, Chronaki CE, Kapidakis S, Nikolaou C, Orphanoudakis SC (1997) An integrated architecture for the provision of health telematic services based on digital library technologies. International Journal on Digital Libraries 1(3):257-277

Tsiknakis M, Katehakis DG, Orphanoudakis SC (2002) An open, component-based information infrastructure for integrated health information networks. International Journal of Medical Informatics 68(1-3):3-26

Tuffs A (2010) Germany puts universal health e-card on hold. British Medical Journal 340(1):c171

TURBOMED (2012) Preisliste \& HzV, Bestellfaxe. http://www.turbomed.de/turbomed/ preisliste. Accessed 2012-05-14

Urgaonkar B, Pacifici G, Shenoy P, Spreitzer M Tantawi A (2007) Analytic modeling of multitier Internet applications. ACM Trans Web 1(1). doi:10.1145/1232722.1232724

VHitG (2006) Arztbrief auf Basis der HL7 Clinical Document Architecture Release 2 für das deutsche Gesundheitswesen - Implementierungsleitfaden. http://download. vhitg.de/Leitfaden-VHitG-Arztbrief-v150. pdf. Accessed 2012-05-14

Vogel O, Arnold I, Chughtai A, Ihler E, Kehrer T, Mehlig U, Zdun U (2009) SoftwareArchitektur: Grundlagen - Konzepte. Spektrum, Heidelberg

Wegner P (1996) Interoperability. ACM Computing Surveys 28(1):285-287

Wu S, Chaudhry B, Wang J, Maglione M, Mojica W, Roth E, Morton SC, Shekelle PG (2006) Systematic review: impact of health information technology on quality, efficiency, and costs of medical care. Annals of Internal Medicine 144(10):742-752

Zimmermann H (1980) OSI reference model the ISO model of architecture for open systems interconnection. IEEE Transactions on Communications 28(4):425-432 